\title{
UTILIZAÇÃO DE COMPOSTO HOMEOPÁTICO NO TRATAMENTO DA MASTITE BOVINA
}

\author{
D.B. Nóbrega ${ }^{1}$, H. Langoni ${ }^{1}$, J.G.F. Joaquim ${ }^{2}$, A.V. da Silva ${ }^{3}$, \\ P.Y.Faccioli ${ }^{1}$, A.V.R. de Matos ${ }^{1}$, B.D. Menozzi ${ }^{1}$
}

${ }^{1}$ Universidade Estadual Paulista, Faculdade de Medicina Veterinária e Zootecnia, Departamento de Higiene Veterinária e Saúde Pública, Distrito de Rubião Júnior, s/noo, CEP 18618-000, Botucatu, SP, Brasil. E-mail: hlangoni@fmvz.unesp.br

\section{RESUMO}

A mastite é uma resposta inflamatória da glândula mamária, sendo a infecção mais frequente do gado destinado a produção leiteira. A utilização de antimicrobianos é prática rotineira para o tratamento desta afecção. O alto custo dos medicamentos e a presença destes como resíduos no leite são fatores que devem ser considerados na terapia convencional. A homeopatia é uma possibilidade de tratamento, que se adequa às mastites, e praticamente a única opção para a obtenção de produtos orgânicos. O objetivo deste trabalho foi avaliar a eficiência do tratamento homeopático, pela realização da prova do Tamis diariamente, e pela contagem de células somáticas, California Mastitis Test - CMT, contagem de unidades formadoras de colônias - UFC, e pela análise da produção diária de leite. Foram selecionados 2 lotes de 50 animais em fase de lactação, estabelecidos previamente pelo proprietário, categorizados como grupo controle e experimental. Foram realizadas quatro coletas de leite, antes da utilização do tratamento, quatro coletas durante o período de tratamento, e uma coleta duas semanas após o seu término. Não foram observadas diferenças significativas quanto a UFC e CCS. Quanto ao CMT, observou-se redução nos casos de mastite subclinica no grupo experimental. $\mathrm{O}$ agente mais comumente isolado foi Corynebacterium bovis em ambos os grupos durante todo o experimento. Quanto à produção de leite, não houve diferença significante estatisticamente entre os dois grupos. Os resultados obtidos no presente trabalho sugerem a utilização de métodos alternativos de tratamento das mastites, e por outro lado mostram a necessidade de novos estudos para se avaliar a eficácia da homeopatia.

PALAVRAS-CHAVE: Mastite, homeopatia, vacas, CCS, UFC

\section{ABSTRACT}

USE OF HOMEOPATIC COMPLEX IN THE TREATMENT OF BOVINE MASTITIS. Mastitis is an inflammatory response of the mammary gland being the most common dairy cattle infection. The antibiotical therapy it's the most common treatment for this disease. However the high cost and the presence of residues in the milk must be considered when choosing the conventional therapy. Homeopathy is a treatment that must be considered in mastitis cases, and it's practically the only option for organic producers. This research aimed to evaluate the effectiveness of homeopathic treatment, through the Tamis test accomplished daily, the Somatic Cell Count - SCC, the California Mastitis Test - CMT, the Colony Forming Units - CFU, and milk production. 100 animals which were part of two lots of 50 animals previously existing in the farm, were chosen by the owner. The lots were classified as control group and experimental group. Four milk collects were realized before the beginning of the study, four during the homeopathic treatment and one at the end of the research. There were no significant differences in CFU and CCS. In the CMT analysis, was verified a decline in the subclinical cases of the experimental group. The most commonly isolated agent was Corynebacterium bovis in both groups throughout the experiment. As for milk production, there was no significant difference between the two groups. The results suggests the use of alternative methods for mastitis control, and showed the need for further studies to evaluate the real effectiveness of the homeopathic treatment.

KEY WORDS: Mastitis, homeopathy, cows, SCC, CFU.

${ }^{2}$ Ministério da Agricultura, Pecuária e Abastecimento, Superintendência Federal de Agricultura, Pecuária e Abastecimento, Unidade Técnica Regional de Agricultura, Pecuária e Abastecimento, Botucatu, SP, Brasil.

${ }^{3}$ Universidade Paranaense, Umuarama, PR, Brasil. 


\section{INTRODUÇÃO}

A mastite bovina é considerada a doença que acarreta os maiores prejuízos econômicos à produção leiteira, pela redução da quantidade, comprometimento da qualidadedoleite, eàs vezes pela perda total da capacidade secretora da glândula mamária (RIBEIRO et al., 2003). O seu impacto negativo segue com o leite além dos portões da fazenda. Mudanças na sua composição como redução do cálcio, fósforo, proteína e gordura, e aumento do sódio e cloro reduzem a sua qualidade. Os antibióticos usados para tratamento das mastites causam grande preocupação para a indústria e para a saúde pública, e o seu resíduo no leite interfere com o processo de manufaturação de muitos produtos lácteos como queijo e outros produtosfermentáveis.

O leite é um alimento fundamental na dieta do homem, de todas as faixas etárias. Produtos lácteos são muito utilizados na alimentação de crianças, o que exige uma atenção maior quanto a qualidade do produto. A qualidade do leite e dos produtos lácteos que chegam aos consumidores é determinada, em grande parte, pela qualidade do leite que é fornecido pelas propriedades rurais (РнILPOT, 1998). Nas infecções crônicas ou subclínicas os sinais clínicos não são visíveis. O seu diagnóstico é obtido por testes indiretos que se baseiam na contagem de células somáticas -CCS. Afeta 10 a $15 \%$ das vacas, em lactação, aumentando a contagem de células inflamatórias, denominadas de celulas somaticas, reduzindo ainda a produção de leite eaumentando a contagem debactérias no leite (HiLLERTON; BERRY, 2005).

A contagem de células somáticas permite o diagnósticodonúmerodeleucócitos presentesnoleite.Em um quarto mamárionãoinfectado, estabeleceu-seque a contagem de células somáticas seja inferior à 200.000 celulas/mL. Contagens mais elevadas estão geralmente associadas a infecções bacterianas (RUEGG, 2001). Este tipo de mastite tende a ser mais prevalente que a mastite clínica na maioria dos países, e pode variar de 19 a $78 \%$, podendo reduzir entre 15 a $45 \%$ a produção de uma vaca durante a lactação (RomAin et al., 2000).

As células somáticas são todas as células presentes no leite, incluindo os leucócitos e células de descamação do epitélio glandular secretor. Os leucócitos, em sua maioria, são mobilizados da corrente sanguínea para o tecido mamário diante de alterações na permeabilidade capilar. Nas infecções intramamárias ocorre um aumento no número de células de defesa passando a predominar neutrófilos, seguidos por macrófagos, linfócitos e o número de células epiteliais permanece inalterado (PHILPOT; NiCKERSON, 1991). As perdas de produção de leite devido ao aumento da CCS são absolutas, isto é, independem donível de produção do animal. A partir de 17.000 células $/ \mathrm{mL}$ tem-se início a redução na produção de leite, mesmo esta sendo bem baixa (Coldebella, 2003).

Um dos grandes desafios no desenvolvimento de novas medidasterapêuticas para prevençãoda mastite é a limitada disponibilidade de drogas. A terapia convencional utiliza antibióticos, entretanto, devido ao alto custo, em alguns momentos torna-se inviável. Existe, portanto, a necessidade do desenvolvimento denovos métodos terapêuticos para o controleefetivo da doença (ERSKINE, 1998). Apesar da disponibilidade de vários antimicrobianos, observa-se a grande resistência dos micro-organismos, pelouso indiscriminado e inadequado, particularmente no Brasil (AlMEIDA et al., 1999). Constata-se o uso indiscriminado de diversos medicamentos veterinários, e há uma preocupação crescente com a presença de resíduos de antibióticos no leite e de tentativas de novas opções de tratamentos menos agressivos, principalmente nos animais de interesse zootécnico (Pontes NetTo et al., 2005).

Tem-se buscado reduzir a incidência de casos de mastite subclínica combinando medidas profiláticas associadas à utilização de antibióticos, fato que onera a produção. Outra desvantagem é que, mesmo com antibiogramas demonstrando in vitro que o agente é sensível a droga, essa sensibilidade varia de 30 a 75\% no animal. O uso de antibióticos diminui a resposta leucocitária na glândula mamária e eles podem a longo prazo gerar resistência microbiana.

A homeopatiaéuma possibilidade de tratamento, nas mastites.É uma terapia específica de estímulo do organismo, na qual a escolha do medicamentoé feita deacordo com os sintomas de cada caso isoladamente (TiefENTHALER, 1996). Apresenta baixo custo e não há necessidade de descarte de leite. Altera a relação custo-benefício, tornando o tratamento da mastite subclínica viável durante a lactação (MANGIERI JUNIOR et al., 2007). As propriedades terapêuticas dos medicamentos homeopáticos ganham espaço na prática veterinária. Há relatos que revelam êxito no tratamento de parasitoses e enfermidades infecciosas, incluindo as mastites (COSTA, 1998). A sua prática para o controle de mastites pode ser indispensável para os sistemas de produção orgânica de leite e a cada dia há maior interesse para a aquisição de leite e seus derivados produzidos de acordo com a filosofia e propostas que regulamentam a produção deste tipo de alimento.

AlmEIDA (2005) constatou que o tratamento tardio com antibiótico apresentou os mesmos resultados quando se utilizou medicamentos homeopáticos, sugerindo a possibilidade de utilização desse tipo de medicamento, mesmo quando o tratamento seiniciar tardiamente. A terapia com antibióticos resulta em 
vantagens a curto prazo quando comparada à homeopatia nos primeiros 20 dias após inicio do tratamento. No decorrer da lactação, não há mais diferenças no que diz respeito a novos casos e contagem de células somáticas (SPRANGER, 2000). No tratamento alopático o objetivo é a eliminação do microorganismo da glândula mamária e, frequentemente, não se verifica diminuição da CCS. O tratamento homeopático, por outro lado, visa produzir uma resposta do hospedeiro (MANGIERI JUNIOR et al., 2007), estimulando a resposta imunológica pois, além de curar, determina imunização indireta, inespecífica e natural, capacitando o organismo a se defender contra os agentes infecciosos (AlmeIDA,1999).

A homeopatia tem sido utilizada como uma terapia veterinária complementar na Europa, principalmente na Alemanha. Também tem mostrado bons resultados no controle da mastite bovina na Índia e outros países (VARSHNEY; NARESH, 2004). Os resultados da pesquisa de MANGIERI JUNIOR et al. (2007) mostraram um aumento médio de $2,5 \mathrm{~kg}$ de leite por animal por dia com a utilização do tratamento homeopático, em um período de 15 dias.

Devido à característica multifatorial da mastite, diversos estudos têm sido desenvolvidos para encontrar novas possibilidades de tratamentos para esta afecção, e desta forma a utilização da homeopatia pode ser uma alternativa interessante, na medida em queelimina o problema de resíduos deantimicrobinos noleite, aspecto relevante para a saúde pública e para a indústria de laticínios. Dessa forma, o objetivo do presente estudo foi verificar a eficácia da utilização de um composto homeopático para o tratamento de mastite, em um rebanho de produção leiteira, pela comparação de alguns parâmetros utilizados, rotineiramente, como indicadores de mastites. Os indicadores utilizados foram a análise do CMT, CCS, UFC, produção leiteira, novas infecções, casos de mastite clínica (Prova do Tamis) e exame microbiológico.

\section{MATERIALEMÉTODOS}

Foram utilizadas 100 vacas de aptidão leiteira, divididas em dois grupos, previamente existentes, de acordo com a produção leiteira, como segue: Grupo 1 (G-1), controle, com 50 animais, que receberam apenas o manejo cotidiano da propriedade, com adição de açúcar cristal na ração, veículo utilizado no compostohomeopático.Grupo 2(G-2), experimental,com 50 animais, tratado com o composto homeopático misturadoa ração, durante dois meses, deacordocom o Quadro 1. Trata-se de propriedade com alta tecnificação com ordenha tipo carrossel, localizada no Município de São Pedro. Os animais apresenta- vamidades variadas, da raça holandesa, com diferentes números de parições distribuídas aleatoriamente entre os dois grupos. Os grupos foram avaliados antes do tratamento durante um mês (período 1), com coletas de leite semanalmente para a realização dos diferentes exames, exceto a prova do Tamis, realizada diariamente. O composto homeopático foi oferecido aos animais do G-2 durante dois meses (período 2) e as colheitas passaram a ser quinzenais, com a prova do Tamis, diariamente para detecção de novos casos demastite.

Os animais de ambos os grupos foram avaliados quanto à produção de leite diária, pela análise dos registros da propriedade. Duas semanas após o término do período 2, realizou-se nova avaliação dos animais dos dois grupos. Foram submetidos aoexame de CMT, segundo SCHALM; NoORLANDER (1957), considerando-se como positivas as reações a partir de uma cruz (+). Foram colhidas amostras de leite em frascos estéreis, após limpeza do teto, lavagem com água corrente, secagem com toalha de papel descartável e utilização de solução de álcool iodado a 5\%, para desinfecção do óstio da teta. Após desprezarem-se os primeiros jatos de leite, foram colhidos ao redor de 10 mL deleite para realização de exame microbiológico, transportados sob temperatura de refrigeração, em caixa isotérmica com gelo reciclável (NMC, 1999). Foram coletadas também amostras de leite para a contagem de células somáticas - CCS e de unidades formadoras de colonias - UFC. A CCS foi realizada eletronicamenteemaparelhoSomacount-300(Bentley) eforam colhidas, independente do resultado doCMT, de ambos os grupos, amostras compostas com aproximadamente $60 \mathrm{~mL}$ de leite, em frascos especiais contendo duas pastilhas de bronopol.

Para o exame microbiológico, inicialmente foram cultivados 0,01 mL de cada amostra, em meios deágar sangue ovino a 8\% e ágar MacConkey, incubando-se a $37^{\circ} \mathrm{C}$, com observação do desenvolvimento microbiano a cada 24 horas, durante 3 dias. As colônias isoladas foram repicadas e estudadas morfologicamente, ecaracterizadas bioquimicamente de acordo com Holt (1994).

A contagem de UFC das amostras de leite compostas de todos os quartos mamários dos animais com pelo menos um quarto positivo ao CMT, nos diferentes momentos, foi realizada cultivando-se $0,1 \mathrm{~mL}$ de leite nas diluições $10^{-1}, 10^{-2}, 10^{-3}$ e $10^{-4}$ em meio de ágar sangue ovino $8 \%$, espalhando-se com alça de Drigalski estéril, de modo a permitir a contagem bacteriana, incubando-se a $37^{\circ} \mathrm{C}$ por 24 horas. A contagem de colônias foi efetuada na diluição onde foi possível estabelecer o limite entre 30 e 300 colônias, calculando-se ao final o número das UFC/ $\mathrm{mL}$ de leite, multiplicando-se por 10 e pelo fator de correção da diluição correspondente. 
Quadro 1 - Medicamentos homeopáticos e potências, utilizados na formulação homeopática, Botucatu, 2008.

\begin{tabular}{|lll|}
\hline Medicamento $^{* *}$ & Potência & Característica do Medicamento* $^{*}$ \\
\hline Phytolacca decandra & $\mathrm{CH} 12$ & Principal. Mastite aguda e crônica, falta de leite \\
Lachesis & $\mathrm{CH} 12$ & Inflamações \\
Belladona & $\mathrm{CH} 12$ & Doenças infecciosas \\
Phosphorus & $\mathrm{CH} 30$ & Sangramentos \\
Bryonia dióica & $\mathrm{CH} 12$ & Inflamações \\
Conium maculatum & $\mathrm{CH} 12$ & Nódulos em glândulas \\
Apis mellifica & $\mathrm{CH} 30$ & Alergias e edema (úbere principalmente) \\
Mercurius solubilis & $\mathrm{CH} 12$ & Catarro, desordens gastrointestinais, dermatites. \\
Pyrogenium & $\mathrm{CH} 6$ & Feridas infeccionadas, falta de assepsia \\
\hline
\end{tabular}

*(Tiefenthaler, 1996).

**Normas da Farmacopeia Homeopática Brasileira.

Durante todo o período experimental, os animais foram examinados previamente a cada ordenha, avaliando-seos primeirosjatos deleiteem caneca defundo negro (prova do Tamis) para diagnóstico de casos clínicos. Em casos de positividade, colheu-se amostra para cultivo microbiano, que foi congelada até o momento da próxima visita. Foram adotados os mesmos procedimentos dehigienização, descritos anteriormente. Realizou-se análise estatística pelo teste não paramétrico U de Mann-Whitney (MEDRONHO, 2004).
Este composto foi adicionado à ração. Dos 1.000 $\mathrm{mL}$ da mistura, preparada em farmácia de manipulação credenciada pela ANVISA, pipetou-se $5 \mathrm{~mL}$, em $500 \mathrm{~g}$ de açúcar cristal, até que a mistura adquiresse característica homogênea. Foi oferecida aos animais duas vezes ao dia, às 5 horas e 16 horas, na ração em toda extensão do cocho por 60 dias, em uma proporção aproximada de $10 \mathrm{~g}$ do preparado/animal. Para o grupo controle, adicionou-se somente açúcar à ração na mesma proporção.

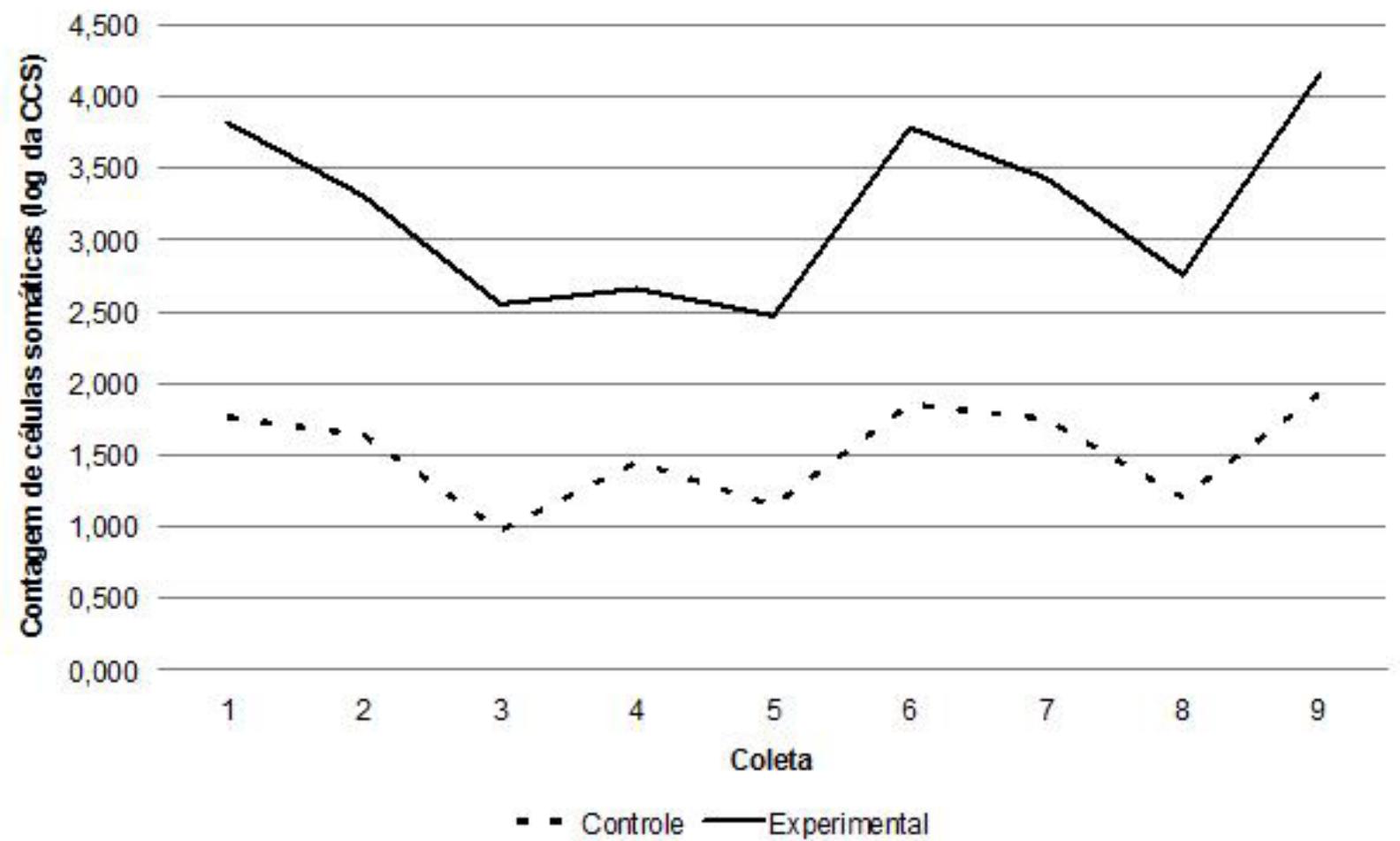

Fig. 1 - Cinética da contagem de células somáticas (log da CCS x 10³/mL) de vacas dos grupos controle e experimental. Botucatu, 2008. 


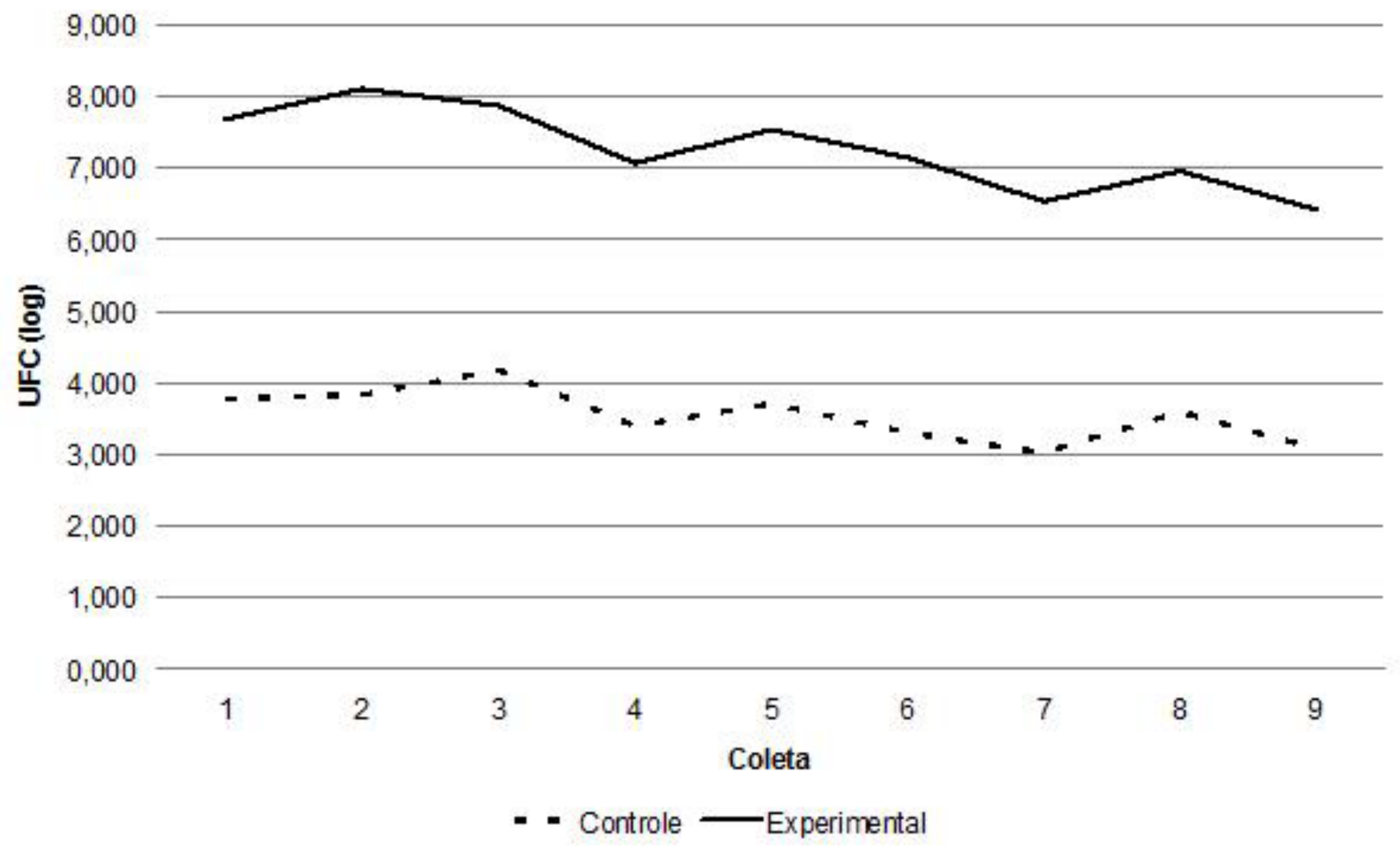

Fig. 2 - Cinética da UFC (log) de vacas de ambos os grupos. Botucatu, 2008.

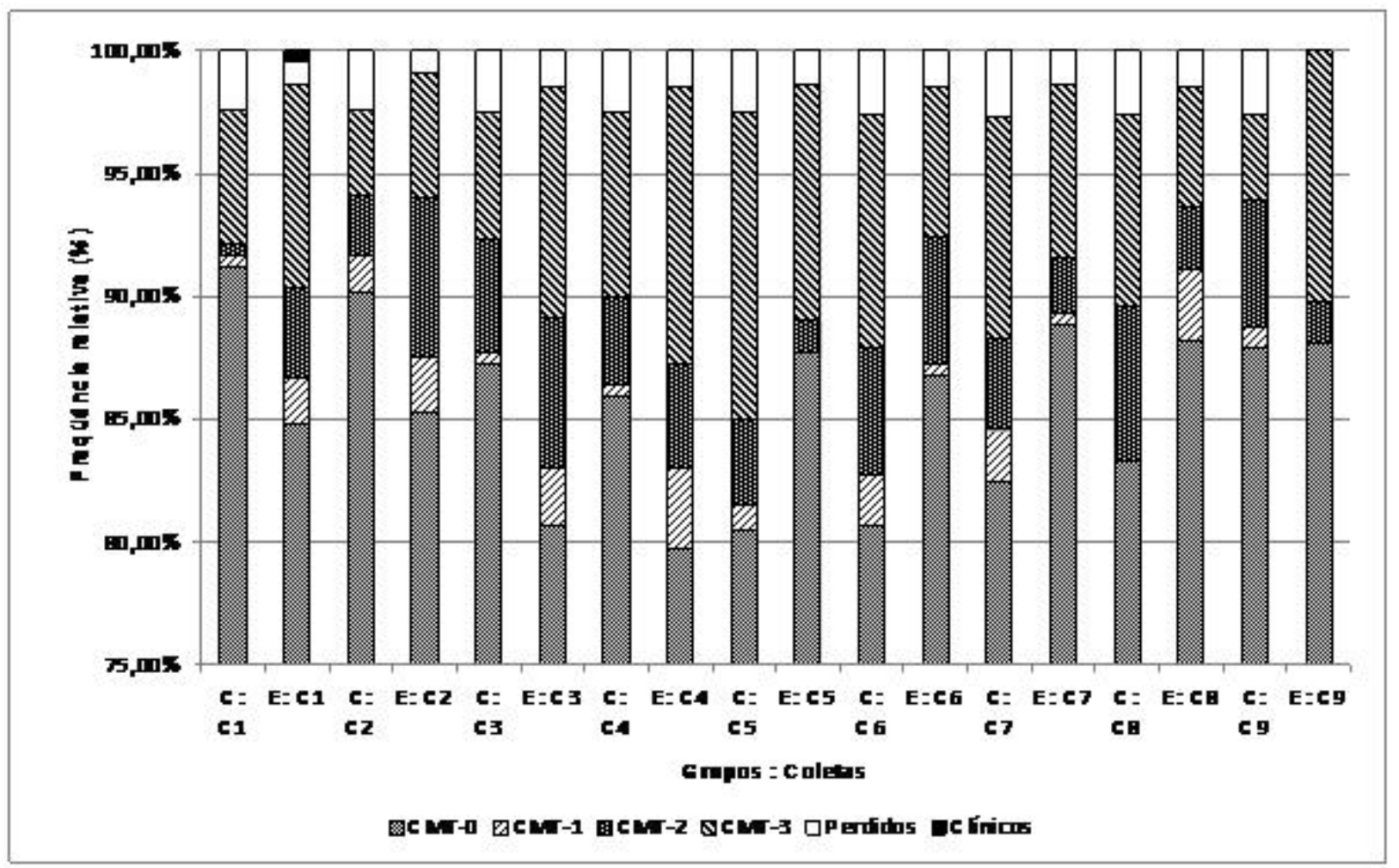

Fig. 3 - Frequências relativas (\%) para amostras de leite classificadas segundo o resultado do CMT, tetos perdidos e casos clínicos nos grupos de vacas controle (C) e experimental (E). Botucatu, 2008. 


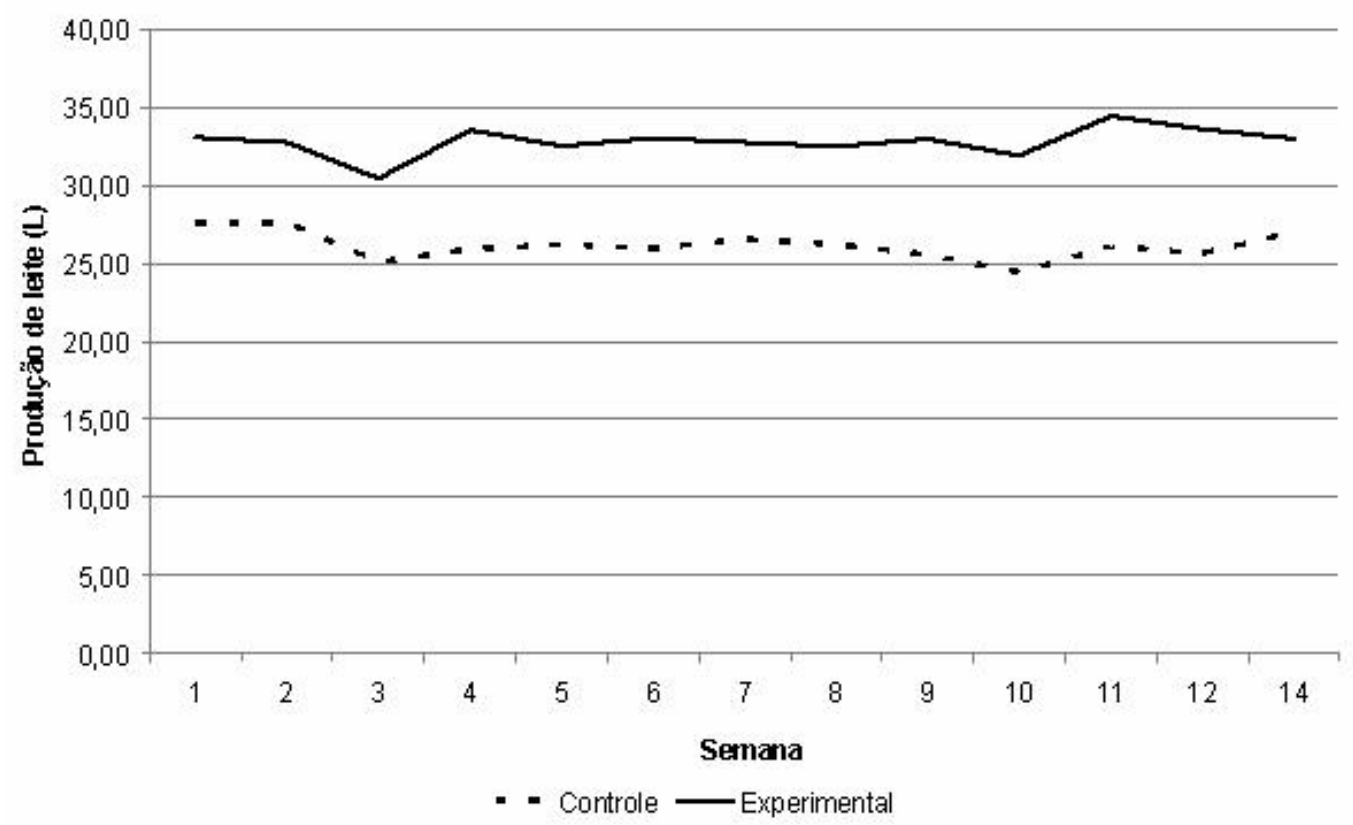

Fig. 4 - Cinética da produção leiteira (L) de vacas do grupo controle e experimental. Botucatu, 2008.

Tabela 1 - Mediana (percentil 25 - percentil 75) dos valores de CCS $\left(\times 10^{3} / \mathrm{mL}\right)$ para as diferentes coletas, nos animais dos grupos controle e experimental. Botucatu. 2008.

\begin{tabular}{cccrc}
\hline Coleta & Controle mediana (P25 - P75) & Experimental mediana (P25 - P75) & Estatística (U) & Valor de P \\
\hline 1 & $81,50(30,50-267,00)$ & $144,00(43,50-552,50)$ & 1098,05 & 0,1440 \\
2 & $90,00(0,00-236,00)$ & $88,50(5,00-296,25)$ & 1371,00 & 0,7244 \\
3 & $4,00^{\mathrm{a}}(0,00-55,75)$ & $95,00^{\mathrm{b}}(2,25-278,00)$ & 856,00 & 0,0032 \\
4 & $13,50(0,25-78,00)$ & $35,00(4,00-155,25)$ & 1162,00 & 0,2223 \\
5 & $7,50(1,25-104,75)$ & $18,50(1,25-152,75)$ & 1207,50 & 0,3553 \\
6 & $87,00(45,25-256,25)$ & $139,00(45,00-234,00)$ & 1321,50 & 0,7338 \\
7 & $98,50(21,25-240,50)$ & $116,00(7,50-187,50)$ & 1291,00 & 0,9759 \\
8 & $20,00(0,00-82,25)$ & $45,00(9,00-141,25)$ & 1046,00 & 0,0944 \\
9 & $78,00(49,00-231,50)$ & $143,50(60,75-552,25)$ & 364,50 & 0,1492 \\
\hline
\end{tabular}

Valores de mediana seguidos de letras minúsculas diferentes indicam diferenças significativas pelo teste de MannWhitney, com $\alpha=0,05$. A coluna "Estatística" mostra o valor de U.

Tabela 2 - Mediana (percentil 25 - percentil 75) dos valores de UFC de vacas dos grupos controle e experimental. Botucatu. 2008.

\begin{tabular}{cccrc}
\hline Coleta & Controle mediana (P25 - P75) & Experimental mediana (P25 - P75) & Estatística (U) & Valor de P \\
\hline 1 & $3000(990-40200)$ & $5900(3125-29750)$ & 67 & 0,6357 \\
2 & $9350(2155-1635)$ & $18400(3900-204000)$ & 6 & 0,1599 \\
3 & $6500(2200-80000)$ & $6650(395-38750)$ & 82 & 0,4798 \\
4 & $1940(1142,5-5050)$ & $2800(1257,5-14125)$ & 123 & 0,4915 \\
5 & $3800(2695-7825)$ & $4800(1630-23850)$ & 124 & 0,9546 \\
6 & $1200(720-3000)$ & $5550(1825-8200)$ & 100,5 & 0,0862 \\
7 & $885(392,5-1722,5)$ & $1040(492,5-45100)$ & 40 & 0,4813 \\
8 & $1930(700-3000)$ & $2400(1215-6150)$ & 109,5 & 0,6045 \\
9 & $1165(665-2670)$ & $1320(610-12500)$ & 47 & 0,7501 \\
\hline
\end{tabular}

Valores de mediana seguidos de letras minúsculas diferentes indicam diferenças significativas pelo teste de MannWhitney, com $\alpha=0,05$. A coluna "Estatística" mostra o valor de U. 


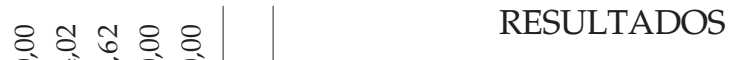

Os resultados são apresentados para as três fases distintas: antes do tratamento (coletas 1,2,3 e 4 período 1), durante o tratamento (coletas 5,6,7 e 8 período 2) e após o tratamento (coleta 9). Na Tabela 1, pode-se observar o comportamento daCCSem todas as coletas. Não houve diferença estatisticamente significativa entre os dois grupos, de acordo com as medianas dos valores deCCS. Noinício a mediana era de $81,50(30,50-267,00)$ para o grupo controle e de $144,00(43,50$ - 552,50) para o experimental. Ao final do fornecimento do composto homeopático ( $8^{\text {a }}$ coleta), os valores eram de $20,00(0,00-82,25)$ para o grupo controle e 45,00 (9,00 - 141,25) para o experimental. A Figura 1 ilustra a cinética da CCS, utilizando-se valores do $\log$ da CCS, nas diferentes coletas. Nota-se que, durante a terceira coleta realizada antes do início do experimento, os grupos apresentaram diferença estatisticamente significativa, fato que não voltou a ocorrer durante o experimento.

Na Tabela 2, encontram-se os resultados da contagem de UFC. A partir das medianas dos valores obtidos nas nove coletas nos dois grupos e pela realização do teste de Mann-Whitney com $\alpha=0,05$ comparando os dois grupos, pode-se notar que não há diferença estatisticamente significativa em nenhum momento do experimento. A Figuar 2 ilustra os valores do log de UFC, e pode-se verificar que o grupo controle mostra menores valores em todas as coletas sendo esta diferença não significativa.

Com relação ao resultado do CMT, na Figura 3 podem ser observadas as frequências relativas em porcentagem de acordo com o grau de reação, além dos tetos perdidos e casos clínicos iagnosticados durante o período de estudo.

Na Tabela 4, podem ser observados os resultados da análise estatística, com as comparações dos resultados do CMT entre os dois grupos, nos três momentos avaliados, ena Tabela 5 podem ser observados os valores referentes às frequências absoluta e relativa em porcentagem, limites inferior e superior do intervalo de confiança a $95 \%$, para os resultados do CMT, nos dois grupos de animais nos diferentes momentos.

Comparando apenas os resultados referentes ao $\mathrm{CMT}$, não se utilizando tetos perdidos e casos de mastites clínicas, independente do grau de positividade ao CMT, a Tabela 6 relaciona todos os resultados, e não das coletas individualmente. Desta forma pode se observar que há diferença estatisticamente significante $(p<0,05)$ entre o grupo controle e experimental nos três períodos. Além disso, há também uma diferença no própriogrupo controlequando se compara os diferentes períodos, bem como no grupoexperimental. 
Tabela 4 - Resultados do teste de $\chi^{2}$ para os três momentos avaliados, comparando os resultados do CMT obtidos entre os dois grupos. Botucatu, 2008.

\begin{tabular}{lcr}
\hline Comparação & $\chi^{2}$ & Valor de P \\
\hline Controle x experimental (Antes) & 25,90 & $<0,0001$ \\
Controle x experimental (Durante) & 12,58 & 0,0135 \\
Controle x experimental (Após) & 10,00 & 0,0404 \\
Antes x Durante x Depois (Controle) & 20,91 & 0,0074 \\
Antes x Durante x Depois (Experimental) & 21,91 & 0,0156 \\
\hline
\end{tabular}

Tabela 5 - Frequência absoluta (nº ), frequência relativa (\%), limites inferior (LI-IC95\%) e superior (LS-IC95\%) do intervalo de confiança a 95\% para amostras de leite de acordo com o resultado do CMT, nos dois grupos, segundo as coletas. Botucatu, 2008.

\begin{tabular}{|c|c|c|c|c|c|c|c|c|c|c|c|}
\hline \multirow[t]{2}{*}{ Coleta } & \multirow[t]{2}{*}{ Amostras } & \multicolumn{4}{|c|}{ Controle } & \multicolumn{4}{|c|}{ Experimental } & \multirow[t]{2}{*}{$\mathrm{p}$} & \multirow[t]{2}{*}{$\mathrm{rr}$} \\
\hline & & № & $\%$ & LI-IC95\% & LS-IC95\% & № & $\%$ & LI-IC95\% & LS-IC95\% & & \\
\hline \multirow[t]{2}{*}{1} & CMT-(-) & 186 & 93,47 & 90,03 & 96,90 & 185 & 86,05 & 81,41 & 90,68 & 0,0153 & 2,136 \\
\hline & CMT-(+) & 13 & 6,53 & 3,10 & 9,97 & 30 & 13,95 & 9,32 & 18,59 & & \\
\hline \multirow[t]{2}{*}{2} & CMT-(-) & 184 & 92,46 & 88,79 & 96,13 & 185 & 86,05 & 81,41 & 90,68 & 0,0403 & 1,851 \\
\hline & CMT-(+) & 15 & 7,54 & 3,87 & 11,21 & 30 & 13,95 & 9,32 & 18,59 & & \\
\hline \multirow[t]{2}{*}{3} & CMT-(-) & 171 & 89,53 & 85,19 & 93,87 & 171 & 81,82 & 76,59 & 87,05 & 0,0330 & 1,736 \\
\hline & CMT-(+) & 20 & 10,47 & 6,13 & 14,81 & 38 & 18,18 & 12,95 & 23,41 & & \\
\hline \multirow[t]{2}{*}{4} & CMT-(-) & 171 & 88,14 & 83,60 & 92,69 & 169 & 80,86 & 75,53 & 86,19 & 0,0543 & 1,614 \\
\hline & CMT-(+) & 23 & 11,86 & 7,31 & 16,40 & 40 & 19,14 & 13,81 & 24,47 & & \\
\hline \multirow[t]{2}{*}{5} & CMT-(-) & 161 & 82,56 & 77,24 & 87,89 & 192 & 88,89 & 84,70 & 93,08 & 0,0880 & 1,569 \\
\hline & CMT-(+) & 34 & 17,44 & 12,11 & 22,76 & 24 & 11,11 & 6,92 & 15,30 & & \\
\hline \multirow[t]{3}{*}{6} & CMT-(-) & 154 & 82,80 & 77,37 & 88,22 & 184 & 88,04 & 83,64 & 92,44 & 0,1529 & 1,438 \\
\hline & CMT-(+) & 32 & 17,20 & 11,78 & 22,63 & 25 & 11,96 & 7,56 & 16,36 & & \\
\hline & CMT-(+) & 32 & 17,20 & 11,78 & 22,63 & 25 & 11,96 & 7,56 & 16,36 & & \\
\hline \multirow[t]{2}{*}{7} & CMT-(-) & 155 & 84,70 & 79,48 & 89,92 & 191 & 90,09 & 86,07 & 94,12 & 0,1259 & 1,545 \\
\hline & CMT-(+) & 28 & 15,30 & 10,08 & 20,52 & 21 & 9,91 & 5,88 & 13,93 & & \\
\hline \multirow[t]{2}{*}{8} & CMT-(-) & 160 & 85,56 & 80,52 & 90,60 & 179 & 89,50 & 85,25 & 93,75 & 0,2808 & 1,375 \\
\hline & CMT-(+) & 27 & 14,44 & 9,40 & 19,48 & 21 & 10,50 & 6,25 & 14,75 & & \\
\hline \multirow[t]{2}{*}{9} & CMT-(-) & 102 & 90,27 & 84,80 & 95,73 & 104 & 88,14 & 82,30 & 93,97 & 0,6746 & 1,219 \\
\hline & CMT-(+) & 11 & 9,73 & 4,27 & 15,20 & 14 & 11,86 & 6,03 & 17,70 & & \\
\hline
\end{tabular}

Tabela 6 - Frequência absoluta $\left(n^{\circ}\right)$, frequência relativa (\%), limites inferior (LI-IC95\%) e superior (LS-IC95\%) do intervalo de confiança a 95\% para amostras de leite de acordo com o resultado do CMT segundo os estágios do experimento, nos dois grupos. Botucatu, 2008.

\begin{tabular}{|c|c|c|c|c|c|c|c|c|c|c|c|}
\hline \multirow[t]{2}{*}{ Estágio } & \multirow[t]{2}{*}{ Amostras } & \multicolumn{4}{|c|}{ Controle } & \multicolumn{4}{|c|}{ Experimental } & \multirow[t]{2}{*}{$\mathrm{p}$} & \multirow[t]{2}{*}{$\mathrm{rr}$} \\
\hline & & № & $\%$ & LI-IC95\% & LS-IC95\% & № & $\%$ & LI-IC95\% & LS-IC95\% & & \\
\hline \multirow[t]{2}{*}{ Antes } & CMT-(-) & 712 & 90,93 & 88,92 & 92,94 & 710 & 83,73 & 81,24 & 86,21 & \multirow[t]{2}{*}{$<0,0001$} & \multirow[t]{2}{*}{1,795} \\
\hline & CMT-(+) & 71 & 9,07 & 7,06 & 11,08 & 138 & 16,27 & 13,79 & 18,76 & & \\
\hline \multirow[t]{2}{*}{ Durante } & CMT-(-) & 630 & 83,89 & 81,26 & 86,52 & 746 & 89,13 & 87,02 & 91,24 & \multirow[t]{2}{*}{0,0028} & \multirow[t]{2}{*}{1,482} \\
\hline & CMT-(+) & 121 & 16,11 & 13,48 & 18,74 & 91 & 10,87 & 8,76 & 12,98 & & \\
\hline \multirow[t]{2}{*}{ Após } & CMT-(-) & 102 & 90,27 & 84,80 & 95,73 & 104 & 88,14 & 82,30 & 93,97 & \multirow[t]{2}{*}{0,7573} & \multirow[t]{2}{*}{1,219} \\
\hline & CMT-(+) & 11 & 9,73 & 4,27 & 15,20 & 14 & 11,86 & 6,03 & 17,70 & & \\
\hline \multirow[t]{2}{*}{ Estatística } & $\chi^{2}$ & & & 18,36 & & & & 10,82 & & & \\
\hline & $\mathrm{P}$ & & & 0,0001 & & & & 0,0045 & & & \\
\hline
\end{tabular}

Estatística: os valores de p e de risco relativo (rr), a direita dos valores das amostras indicam a comparação entre grupos controle e experimental nos diferentes momentos; os valores de $c^{2}$ e p, abaixo dos valores das amostras, indicam a comparação entre momentos para um mesmo grupo. 
Tabela 7 - Frequência absoluta $\left(\mathrm{n}^{\circ}\right.$ ), frequência relativa (\%), limites inferior (LI-IC95\%) e superior (LS-IC95\%) do intervalo de confiança a 95\% para amostras de leite classificadas segundo o microrganismo, isolado de vacas dos dois grupos, nas diferentes fases do experimento. Botucatu, 2008.

\begin{tabular}{|c|c|c|c|c|c|c|c|c|}
\hline \multirow[b]{2}{*}{ Antes } & \multicolumn{4}{|c|}{ Controle } & \multicolumn{4}{|c|}{ Experimental } \\
\hline & № & $\%$ & LI-IC95\% & LS-IC95\% & № & $\%$ & LI-IC95\% & LS-IC95\% \\
\hline Corynebacterium bovis & 35 & 45,45 & 34,33 & 56,58 & 54 & 30,34 & 23,58 & 37,09 \\
\hline Corynebacterium spp. & 2 & 2,60 & $-0,96$ & 6,15 & 0 & 0,00 & 0,00 & 0,00 \\
\hline Streptococcus agalactiae & 0 & 0,00 & 0,00 & 0,00 & 2 & 1,12 & $-0,42$ & 2,67 \\
\hline Streptococcus dysgalactiae & 3 & 3,90 & $-0,43$ & 8,22 & 19 & 10,67 & 6,14 & 15,21 \\
\hline Streptococcus pyogenes & 0 & 0,00 & 0,00 & 0,00 & 1 & 0,56 & $-0,54$ & 1,66 \\
\hline Streptococcus bovis & 0 & 0,00 & 0,00 & 0,00 & 1 & 0,56 & $-0,54$ & 1,66 \\
\hline Escherichia coli & 2 & 2,60 & $-0,96$ & 6,15 & 21 & 11,80 & 7,06 & 16,54 \\
\hline Staphylococcus epidermidis & 13 & 16,88 & 8,52 & 25,25 & 17 & 9,55 & 5,23 & 13,87 \\
\hline Staphylococcus aureus & 4 & 5,19 & 0,24 & 10,15 & 4 & 2,25 & 0,07 & 4,42 \\
\hline Candida spp. & 0 & 0,00 & 0,00 & 0,00 & 6 & 3,37 & 0,72 & 6,02 \\
\hline Streptococcus uberis & 1 & 1,30 & $-1,23$ & 3,83 & 9 & 5,06 & 1,84 & 8,27 \\
\hline Bacillus spp. & 0 & 0,00 & 0,00 & 0,00 & 1 & 0,56 & $-0,54$ & 1,66 \\
\hline Pseudomonas aeruginosa & 1 & 1,30 & $-1,23$ & 3,83 & 0 & 0,00 & 0,00 & 0,00 \\
\hline Klebsiella pneumoniae & 0 & 0,00 & 0,00 & 0,00 & 1 & 0,56 & $-0,54$ & 1,66 \\
\hline Klebsiella oxytoca & 0 & 0,00 & 0,00 & 0,00 & 0 & 0,00 & 0,00 & 0,00 \\
\hline Enterobacter aerogenes & 0 & 0,00 & 0,00 & 0,00 & 2 & 1,12 & $-0,42$ & 2,67 \\
\hline $\mathrm{NC}^{*}$ & 3 & 3,90 & $-0,43$ & 8,22 & 2 & 1,12 & $-0,42$ & 2,67 \\
\hline Negativos & 13 & 16,88 & 8,52 & 25,25 & 38 & 21,35 & 15,33 & 27,37 \\
\hline Conferencia & 77 & & & & 178 & & & \\
\hline \multicolumn{9}{|l|}{ Durante } \\
\hline Corynebacterium bovis & 41 & 31,06 & 23,17 & 38,95 & 31 & 21,09 & 14,49 & 27,68 \\
\hline Corynebacteriu m spp. & 0 & 0,00 & 0,00 & 0,00 & 0 & 0,00 & 0,00 & 0,00 \\
\hline Streptococcus agalactiae & 1 & 0,76 & $-0,72$ & 2,24 & 0 & 0,00 & 0,00 & 0,00 \\
\hline Streptococcus dysgalactiae & 1 & 0,76 & $-0,72$ & 2,24 & 1 & 0,68 & $-0,65$ & 2,01 \\
\hline Streptococcus pyogenes & 5 & 3,79 & 0,53 & 7,04 & 20 & 13,61 & 8,06 & 19,15 \\
\hline Streptococcus bovis & 0 & 0,00 & 0,00 & 0,00 & 7 & 4,76 & 1,32 & 8,20 \\
\hline Escherichia coli & 1 & 0,76 & $-0,72$ & 2,24 & 18 & 12,24 & 6,95 & 17,54 \\
\hline Staphylococcus epidermidis & 16 & 12,12 & 6,55 & 17,69 & 8 & 5,44 & 1,77 & 9,11 \\
\hline Staphylococcus aureus & 6 & 4,55 & 0,99 & 8,10 & 1 & 0,68 & $-0,65$ & 2,01 \\
\hline Candida spp. & 0 & 0,00 & 0,00 & 0,00 & 1 & 0,68 & $-0,65$ & 2,01 \\
\hline Streptococcus uberis & 6 & 4,55 & 0,99 & 8,10 & 5 & 3,40 & 0,47 & 6,33 \\
\hline Bacillus spp. & 0 & 0,00 & 0,00 & 0,00 & 0 & 0,00 & 0,00 & 0,00 \\
\hline Pseudomonas aeruginosa & 0 & 0,00 & 0,00 & 0,00 & 0 & 0,00 & 0,00 & 0,00 \\
\hline Klebsiella pneumoniae & 1 & 0,76 & $-0,72$ & 2,24 & 9 & 6,12 & 2,25 & 10,00 \\
\hline Klebsiella oxytoca & 0 & 0,00 & 0,00 & 0,00 & 7 & 4,76 & 1,32 & 8,20 \\
\hline Enterobacter aerogenes & 2 & 1,52 & $-0,57$ & 3,60 & 1 & 0,68 & $-0,65$ & 2,01 \\
\hline NC & 1 & 0,76 & $-0,72$ & 2,24 & 1 & 0,68 & $-0,65$ & 2,01 \\
\hline Negativos & 51 & 38,64 & 30,33 & 46,94 & 37 & 25,17 & 18,15 & 32,19 \\
\hline Conferencia & 132 & & & & 147 & & & \\
\hline \multicolumn{9}{|l|}{ Após } \\
\hline Corynebacterium bovis & 7 & 58,33 & 30,44 & 86,23 & 7 & 25,00 & 8,96 & 41,04 \\
\hline Corynebacterium spp & 0 & 0,00 & 0,00 & 0,00 & 0 & 0,00 & 0,00 & 0,00 \\
\hline Streptococcus agalactiae & 0 & 0,00 & 0,00 & 0,00 & 0 & 0,00 & 0,00 & 0,00 \\
\hline Streptococcus dysgalactiae & 0 & 0,00 & 0,00 & 0,00 & 1 & 3,57 & $-3,30$ & 10,45 \\
\hline Streptococcus pyogenes & 2 & 16,67 & $-4,42$ & 37,75 & 3 & 10,71 & $-0,74$ & 22,17 \\
\hline
\end{tabular}

Continua... 
Tabela 7 - Continuação.

\begin{tabular}{|c|c|c|c|c|c|c|c|c|}
\hline \multirow[b]{2}{*}{ Antes } & \multicolumn{4}{|c|}{ Controle } & \multicolumn{4}{|c|}{ Experimental } \\
\hline & № & $\%$ & LI-IC95\% & LS-IC95\% & № & $\%$ & LI-IC95\% & LS-IC95\% \\
\hline Streptococcus bovis & 0 & 0,00 & 0,00 & 0,00 & 1 & 3,57 & $-3,30$ & 10,45 \\
\hline Escherichia coli & 0 & 0,00 & 0,00 & 0,00 & 0 & 0,00 & 0,00 & 0,00 \\
\hline Staphylococcus epidermidis & 1 & 8,33 & $-7,30$ & 23,97 & 4 & 14,29 & 1,32 & 27,25 \\
\hline S. aureus & 0 & 0,00 & 0,00 & 0,00 & 3 & 10,71 & $-0,74$ & 22,17 \\
\hline Candida spp. & 0 & 0,00 & 0,00 & 0,00 & 0 & 0,00 & 0,00 & 0,00 \\
\hline Streptococcus uberis & 0 & 0,00 & 0,00 & 0,00 & 7 & 25,00 & 8,96 & 41,04 \\
\hline Bacillus spp. & 0 & 0,00 & 0,00 & 0,00 & 0 & 0,00 & 0,00 & 0,00 \\
\hline Pseudomonas aeruginosa & 0 & 0,00 & 0,00 & 0,00 & 0 & 0,00 & 0,00 & 0,00 \\
\hline Klebsiella pneumoniae & 0 & 0,00 & 0,00 & 0,00 & 1 & 3,57 & $-3,30$ & 10,45 \\
\hline Klebsiella oxytoca & 0 & 0,00 & 0,00 & 0,00 & 0 & 0,00 & 0,00 & 0,00 \\
\hline Enterobacter aerogenes & 0 & 0,00 & 0,00 & 0,00 & 0 & 0,00 & 0,00 & 0,00 \\
\hline $\mathrm{NC}$ & 0 & 0,00 & 0,00 & 0,00 & 0 & 0,00 & 0,00 & 0,00 \\
\hline Negativos & 2 & 16,67 & $-4,42$ & 37,75 & 1 & 3,57 & $-3,30$ & 10,45 \\
\hline Conferencia & 12 & & & & 28 & & & \\
\hline
\end{tabular}

${ }^{*} \mathrm{NC}=$ não classificado.

Tabela 8 - Resultados do teste de $c^{2}$ para os três momentos avaliados, de acordo com o resultado do exame microbiológico, obtidos entre os dois grupos. Botucatu, 2008.

\begin{tabular}{lrr}
\hline Comparação & \multicolumn{1}{c}{$\chi^{2}$} & Valor deP \\
\hline Controle x experimental (antes) & 32,94 & 0,0075 \\
Controle x experimental (durante) & 56,24 & $<0,0001$ \\
Controle x experimental (depois) & 10,63 & 0,2233 \\
Antes x durante x após (controle) & 41,24 & 0,0293 \\
Antes x durante x após (experimental) & 109,06 & $<0,0001$ \\
\hline
\end{tabular}

Tabela 9 - Média \pm desvio-padrão dos valores da produção de leite (L) de vacas dos grupos controle e experimental, segundo as semanas de coleta. Botucatu. 2008.

\begin{tabular}{|c|c|c|c|c|}
\hline \multirow[b]{2}{*}{ Semana } & \multirow{2}{*}{$\begin{array}{c}\text { Controle } \\
\text { Média } \pm \text { Desvio-padrão }\end{array}$} & \multirow{2}{*}{$\begin{array}{c}\text { Experimental } \\
\text { Média } \pm \text { Desvio-padrão }\end{array}$} & \multicolumn{2}{|c|}{ Estatística } \\
\hline & & & $\mathrm{T}$ & $\mathrm{p}$ \\
\hline 1 & $27,61^{\mathrm{a}} \pm 4,47$ & $33,09^{b} \pm 6,31$ & 5,10 & $<0,0001$ \\
\hline 2 & $27,59^{a} \pm 5,29$ & $32,77^{b} \pm 6,19$ & 4,59 & $<0,0001$ \\
\hline 3 & $25,12^{a} \pm 5,56$ & $30,44^{b} \pm 7,15$ & 4,01 & 0,0001 \\
\hline 4 & $25,93^{a} \pm 5,01$ & $33,55^{\mathrm{b}} \pm 7,67$ & 5,99 & $<0,0001$ \\
\hline 5 & $26,24^{a} \pm 5,82$ & $32,52^{b} \pm 8,26$ & 4,45 & $<0,0001$ \\
\hline 6 & $25,97^{a} \pm 5,91$ & $33,01^{b} \pm 7,71$ & 5,19 & $<0,0001$ \\
\hline 7 & $26,58^{a} \pm 6,14$ & $32,77^{b} \pm 7,63$ & 4,53 & $<0,0001$ \\
\hline 8 & $26,22^{a} \pm 6,65$ & $32,51^{b} \pm 8,04$ & 4,33 & $<0,0001$ \\
\hline 9 & $25,57^{a} \pm 6,56$ & $32,98^{b} \pm 7,86$ & 5,13 & $<0,0001$ \\
\hline 10 & $24,44^{\mathrm{a}} \pm 6,97$ & $31,91^{\mathrm{b}} \pm 8,08$ & 4,99 & $<0,0001$ \\
\hline 11 & $26,10^{a} \pm 6,27$ & $34,42^{b} \pm 8,03$ & 5,72 & $<0,0001$ \\
\hline 12 & $25,64^{a} \pm 6,36$ & $33,62^{b} \pm 7,78$ & 5,56 & $<0,0001$ \\
\hline 14 & $27,04^{a} \pm 5,00$ & $33,00^{b} \pm 6,78$ & 4,99 & $<0,0001$ \\
\hline
\end{tabular}

Estatística: Valores de média seguidos de letras minúsculas diferentes indicam diferenças significativas pelo teste $t$ de Student, com $\alpha=0,05$. 
Tabela 10 - Valores da média \pm desvio-padrão da produção de leite (L) de vacas dos grupos controle e experimental, segundo os períodos de coleta. Botucatu. 2008.

\begin{tabular}{llcrr}
\hline Período & Controle & Experimental & Estatística & Valor de P \\
\hline $1-4$ (Antes) & $26,61 \pm 5,16$ & $32,50 \pm 6,91$ & 9,736 & $<0,0001$ \\
$5-12$ (Durante) & $25,84 \pm 6,32$ & $32,96 \pm 7,89$ & 14,161 & $<0,0001$ \\
14 (Após) & $27,04 \pm 5,00$ & $32,99 \pm 6,78$ & 4,994 & $<0,0001$ \\
\hline Estatística & 1,675 & 0,2784 & & \\
\hline Valor de P & 0,1881 & 0,7571 & &
\end{tabular}

Estatística: $\left({ }^{*}\right)$ Valores corrigidos pelo número de coletas. Para um mesmo período, valores de P menores que 0,05 indicam diferenças significativas entre as áreas das curvas de produção entre os grupos Controle e Experimental, pelo teste $t$ de Student, com $\alpha=0,05$. Para um mesmo grupo, valores de P menores que 0,05 indicam diferenças significativas entre as áreas das curvas de produção entre os períodos de coleta, pelo teste t de Student, com $\alpha=0,05$.

Tabela 11 - Valores da média \pm desvio-padrão dos valores área da curva de produção de leite (L) de vacas dos grupos controle e experimental, segundo os períodos de coleta. Botucatu. 2008.

\begin{tabular}{lcccc}
\hline Período & Controle & Experimental & Estatística & Valor de P \\
\hline $1-14$ & $229,00 \pm 57,39$ & $288,98 \pm 64,60$ & 5,019 & $<0,0001$ \\
$1-4^{*}$ & $19,13 \pm 4,47$ & $23,57 \pm 5,21$ & 6,672 & $<0,0001$ \\
$5-12^{*}$ & $21,91 \pm 6,40$ & $28,18 \pm 7,08$ & 4,752 & $<0,0001$ \\
\hline Valor de P & $<0,0001$ & $<0,0001$ & &
\end{tabular}

Estatística: $\left(^{*}\right)$ Valores corrigidos pelo número de coletas. Para um mesmo período, valores de P menores que 0,05 indicam diferenças significativas entre as áreas das curvas de produção entre os grupos Controle e Experimental, pelo teste $t$ de Student, com $\alpha=0,05$. Para um mesmo grupo, valores de P menores que 0,05 indicam diferenças significativas entre as áreas das curvas de produção entre os períodos de coleta, pelo teste t de Student, com $\alpha=0,05$.

Ogrupoexperimental apresenta maior númerode resultados negativos ao CMT antes doinicío do tratamento. O mesmo não se observa no grupo controle, que mostra um aumento no número de resultados positivos. Essas diferenças são estatisticamente significantes de acordo com a Tabela 6. Os resultados referentes ao isolamento microbiano, contendo as frequências absoluta e relativa em porcentagem, o limite inferior e superior com intervalo de confiança de $95 \%$ de acordo com os micro-organimos isolados nos dois grupos nas três fases do experimento, são apresentados na Tabela 7.

Corynebacteriumbovis foi oagentemais comumente isolado em ambos os grupos nos diferentes períodos. Há diferença estatística entre os grupos, quando se agrupa as coletas do início do fornecimento do produto. Os isolamentos realizados no grupo controle, no período 1, foram 77, e no período 2,132, fato que pode ser explicado pelas culturas terem se baseado nos resultados do CMT. No decorrer do experimento, os grupos diferiram também quanto à distribuição dos resultados microbianos. Pode-se notar pela Tabela 8, que o grupo experimental sofreu uma alteração bastante significativa quando se compara os três períodos analisados.
Quanto à produção leiteira, os resultados obtidos em cada coleta, com os valores médios, nos dois grupos, bem como a comparação entre eles nas diferentes coletas, e os valores do teste $t$ de student e de $p$, podem ser apreciados na Tabela 9.

Há diferenças em todas as coletas, mesmo no início do experimento. Verifica-se também que o grupo experimental revelou sempre os melhores índices quanto a produção de leite, diferentemente do observado para outras variaveis como CCS e UFC. Não se pode concluir que há diferença significativa. O ideal é a comparação do grupo experimental entre si mesmo nos diferentes momentos para verificar se há alteração na produção de leite, da mesma forma que para o grupo controle para se descartar possíveis influências externas, como mostra a Tabela 10.

Além dos grupos diferirem entre si nos diferentes momentos, eles apresentam diferenças significativas quando comparados a si próprios. Tal fato não permite concluir se há diferença significativa com a utilização do produto quando se avalia a produção leiteira. Pode-se salientar que a produção do grupo experimental aumentou quando se compara o período 1 (antes) eo período 2 (durante) $(32,5 \times 32,96)$ eno grupo 
controleocorreu diminuiçãodaprodução(26,61 x25,84), entretanto, não significativa estatisticamente. A Tabela 11 mostra a comparação entre os grupos quando analisada a área da curva de produção de ambos os grupos, também agrupados deacordo com os períodos analisados, como ilustra a Figura 4. Há diferenças entre os dois grupos em todos os momentos, quando comparados entreeleseasimesmos, nãosendopossível concluirque a utilização do composto homeopático aumentou a produção leiteira, fato que deveria estar relacionado a uma diminuição da ocorrência de mastites.

\section{DISCUSSÃO}

A homeopatia é uma opção inclusive para o tratamento de mastites clínicas (Hovi; RoDERICK, 1998). Diferentes protocolos são utilizados, o que dificulta a sua recomendação na prática diária e há diferenças entre os resultados obtidos, indicando a necessidade de estudos para definição das condutas homeopáticas (BENITES, 2005).

As células somáticas são células de defesa do próprio animal. Elas migram do sangue para o interior da glândula mamária com o objetivo de combater agentes agressores, responsáveis pela infecção (PEREIRA, 2001). No presente estudo não houve diferença estatisticamente significante no que se refere à contagem de UFC e CCS. Para a CCS, Benites (2005) não observou diferença estatisticamente significante entre grupo tratado com medicamento homeopático e grupo controle, em casos de mastite subclínica. A elevada CCS poderia demonstrar a capacidade de controlar o micro-organismo no foco de infecção, impedindo a evolução para mastite clínica. Este autor não observou a evolução de casos de mastite subclínica para clínica, podendo-se considerar um aspecto favorável do tratamento homeopático. No mesmoestudo observou-seum aumento na produção de leite nos animais com mastite subclínica.

Ocomportamento daCCS, no presente estudo, de acordo com a Tabela 1 mostra sua diminuição nas coletas 6,7 e 8, durante a utilização do composto homeopático, fato não verificado no grupo controle. Além disso, diferenças estatisticamente significantes entre os grupos como ocorrido na coleta 3 não voltou a acontecer, mostrando uma maior similaridade entre grupos distintos inicialmente como mostrou a coleta 3. A alta contagem de células somáticas é observada frequentemente em quartos mamários infectados e, devido a alta frequência de infecções intramamárias nos rebanhos, a maioria dos quartos classificados comonão infectados pode ter sido infectadoem outro momento da lactação atual ou anterior e, segundo Ogola et al. (2007), é possível a manutenção de altas CCS em infecções já eliminadas.
Notratamento alopático, queobjetiva a eliminação domicro-organismoda glândula mamária, frequentementenãoseverifica diminuição daCCS. Otratamento homeopático visa produziruma resposta dohospedeiro, capaz de eliminar o micro-organismo, o que pode explicar a celularidade do leite sempre em níveis mais altos do que o grupo controle, nesta pesquisa.

O comportamento da contagem de UFC mostrou oscilação nos dois grupos, nos vários momentos, com diferenças entre eles, entretanto não significantes estatisticamente. Fato semelhante foi observado por AlmeIDA et al. (1999) que verificaram uma elevação no número de colônias, em diferentes momentos. No presente estudo, entretanto, ocorreu elevaçãono períododequatrosemanas, com diminuição subsequente. Ambos os valores das medianas das UFC aumentaram na coleta 8 , entretanto, não significante estatisticamente, contrariando o principio homeopático de reação do organismo, pois esperava-se que a contagem de UFC no grupo experimental dimuisse. A elevação no número de colônias isoladas entre as duas coletas iniciais e redução subsequente pode ser explicada pelo princípio da homeopatia, pois, inicialmente, há uma exacerbação da enfermidade (Princípio da Agravação Homeopática), com posterior reação do organismo. Segundo o princípio homeopático, os medicamentos utilizados devem ser capazes de provocar inicialmente uma resposta similar ao processo patológico, o que pode justificar a elevação inicial da contagem de UFC (TIEFENTHALER, 1996).

OCMT estima o conteúdo de células somáticas no leite. Dependendo da interpretação dos escores, o CMT pode produzir resultados falso-positivos ou falso-negativos (BRITo et al., 1997). BARBOSA et al. (2002) analisaram a correlação entre CMT e CCS e verificaram que das 160 amostras analisadas $91,87 \%$ mostraram correlação positiva entre CCS e CMT, sendo a maioria amostras com baixa celularidade $(<500.000$ células $/ \mathrm{mL}$ ). Na Figura 3, nota-se que inicialmente o grupo controle apresentava uma frequência de resultados negativos mais elevada do que o grupo experimental. Observa-se que a partir da coleta 5 a relação inverteu, pois o grupo experimental passou a apresentarmaiornúmeroderesultadosnegativos aoCMT, e menor número de reações três cruzes $(+++)$. Essa relação a partir da coleta 9 inverteu-se novamente, passando o grupo experimental a apresentar maior número de reações três cruzes $(+++)$, e o número de casos negativos praticamente iguais. O período que coincide com a maior frequência de resultados negativos para o grupo experimental, e menor número de reações três cruzes, é o período de administração do composto homeopático (coletas 5,6,7 e 8).

Quando se analisa apenas os resultados positivos independentemente das reações ao CMT, observa-se diferença entre os grupos. A Tabela 5 mostra diferença 
significante, diferentemente do observado quando se comparam os resultados de acordo com o grau de reação do CMT. Evidencia-se que os dois grupos eram inicialmente diferentes, pois a propriedade separa os lotes deanimais por produção. Ogrupo controleapresentava menor produção que o grupo experimental, entretanto melhores resultados doCMT, inicialmente.

A homeopatia resultou em uma reduçãonos casos subclínicos detectados pelo CMT, o que pode significar resposta dos animais contra a infecção (BENITES, 2005). O CMT mostrou-se mais eficiente que a CCS para avaliar o tratamento homeopático. Observou-se redução na ocorrência de casos subclínicos peloCMT. Este fato sugere que em rebanhos com menor concentração deCCSnoleite se conclua que não ocorra efeito favorável da homeopatia. O CMT mostrou melhor resultado, mesmo sendo uma prova de menor especificidade, sujeita a subjetividade de interpretação do examinador. Têm-se estabelecido limites de 100.000 até 500.000 CCS/mL de leite sem necessariamente a ocorrência de infecção intramamária (BRITO et al., 1997). A mediana dos valores de CCS nas diferentes coletas estão abaixo do limiar de 500.000 células por $\mathrm{mL}$, fato também observado no início do experimento para ambos os lotes. Desta forma, a utilização de rebanhos com maior CCS no leite poderia facilitar a interpretação dos resultados do tratamento homeopático na mastite bovina.

SEARCY et al. (1995) utilizaram para tratamento da mastite subclínica um complexo homeopático compostode Phytolacca decandra $200 \mathrm{CH}$, Phosphorus $200 \mathrm{CH}$ e Conium maculatum 200CH, obtendo resultados significantes quando comparado ao grupo controle, que mostrou uma ocorrência de mastites 4,53 vezes maior quando comparada ao grupo tratado, a partir da avaliação pelo CMT.

C. bovis foi mais isolado em ambos os grupos, nos três períodos. Observou-se também alta porcentagem de resultados de isolamentos negativos, sendo maior no período de tratamento, o que pode ser atribuído a diversos fatores como: resíduos de antibióticos, exigência de condições específicas para crescerem, animais com alta celularidade no leite, porém sem infecção mamária, como início e final de lactação, mastites traumáticas, técnica inadequada de isolamento, tempo inadequado para crescimento do agente, entre outros. Resultados positivos ao CMT com baixo escore, podem ser negativos ao exame microbiológico.

Onúmero de amostras positivas ao CMT foi maior no grupo controle durante o período de tratamento, $\mathrm{o}$ que pode explicar o maior número de resultados negativos aoexame microbiológico. MANGIERIJUNIORet al. (2007) observaram que com o tratamentohomeopático houve redução na frequência de isolamentos de C. bovis, C. ulcerans e Corynebacterium spp. No presente estudo verificou-se também diminuiçãono isolamen- to de C. bovis, porém outros agentes passaram a ser isolados com maior frequência. Para Corynebacterium bovis, o CMT revelou uma baixa sensibilidade, sendo recomendado tambem o exame da CCS para diagnosticar mastites por este agente. É possível também que quartos mamários negativos ao CMT apresentem infecção por patógenos como S. aureus, constituindo-se em fonte deinfecção para o rebanho(BRITO et al.,1999), considerando-se a alta contagiosidade desse patógeno.

Quanto a produção leiteira, não foi possível concluir se houve diferença significante entre os grupos, pois os lotes não eram homogêneos, e pelo fato do próprio grupo controle diferir entre si nos períodos. MANGIERI JUNIOR et al. (2007) verificaram que, apesar da presença do micro-organismo na glândula mamária e de elevadas CCS no leite no grupo de animais tratados, possivelmente tenha ocorrido diminuição do processo inflamatório, pois observaram um aumento médio da produção de leite de $2,5 \mathrm{~kg} /$ dia nos animais tratados. Provavelmente a presença do microorganismo estimule a produção e manutenção de células somáticas em níveis elevados com consequente resposta imune celular da glândula mamária.

Com relaçãoaos casos de mastite subclínica, BENITES (2005) não observou diferenças quanto à CCS e no exame microbiológico, após a utilização de tratamento com antibióticos e homeopatia. Por outro lado, observou um aumento de $2,5 \mathrm{~kg}$ de leite por dia no grupo tratado com homeopatia, demonstrando uma possível redução no processo inflamatório einfecção, da mesma forma que MANGIERI JUNIOR et al. (2007).

Nas condições do presenteestudopode-se concluir que o tratamento homeopático produz uma resposta dohospedeirona tentativa deinativaromicro-organismo, fato evidenciado pela maior celularidade do leite nos animais. Tanto a CCS como UFC não foram os melhores métodos para avaliar o efeito do tratamento homeopático. O CMT mostrou-se como ferramenta importante no diagnóstico dos casos subclínicos e podeserutilizado para avaliaçãodo tratamentohomeopático. Pode-se concluir ainda que o leite com alta celularidadenem sempreindica processoinflamatório da glândula mamária. O composto homeopático não interferiu de forma significativa na produção leiteira, apesar da redução de casos subclínicos. Sugere-se a realização de novos estudos para avaliação da homeopatia no tratamento das mastites.

\section{Agradecimentos}

À Fundação de Amparo à Pesquisa do Estado de São Paulo (FAPESP) pela concessão de bolsa de Iniciação Científica - Processo 2006/05086-7 e de Apoio Técnico - Processo 2006/01049-0. 


\section{REFERENNCIAS}

ALMEIDA, A.C.; FONSECA, Y.M.; SOARES, T.M.P.; SILVA, D.B.; BUELTA, T.T.M.; SILVA, G.L.M.E. Tratamento de mastite subclínica em bovinos utilizando bioterapia. Revista da Universidade de Alfenas, v.5, p.199203, 1999.

ALMEIDA, L.A.B.; BRITO, M.A.V.P.; BRITO, J.R.F.; PIRES, M.F.A.; BENITES, N.R. Tratamento de mastite clínica experimental por meio de ordenhas múltiplas em vacas leiteiras inoculadas com Staphylococcus aureus. Arquivos do Instituto Biológico, São Paulo, v.72, n.1, p.1-6, 2005.

BARBOSA, C.P.; BENEDETTI, E.; RIBEIRO, S.C.A.; GUIMARÃES, E.C. Relação entre contagem de células somáticas (CCS) e os resultados do "Califórnia mastitis test" (CMT), no diagnóstico da mastite bovina. Bioscience Journal, v.18, n.1, p.93-102, 2002.

BENITES, N. R. Comparação entre tratamento homeopático de mastite bovina clínica e subclínica. 2005. 116f. Tese (Livre docência) - Faculdade de Medicina Veterinária e Zootecnia, Universidade Estadual Paulista, São Paulo, 2005.

BENITES, N.R.; GUERRA, J.L.; MELVILLE, P.A.; COSTA, E.O. A etiology and histopathology of bovine mastitis of spontaneous occurrence. Journal of Veterinary Medicine, v.49, p.366-370, 2002.

BRITO, J.R.F.; CALDEIRA, G.A.V.; VERNEQUE, R.S.; BRITO, M.A.V.P. Sensibilidade e especificidade do Califórnia mastitis test como recurso diagnóstico da mastite subclínica em relação à contagem de células somáticas. Pesquisa Veterinária Brasileira, v.17, n.2, p.4953, 1997.

BRITO, M.A.V.P.; BRITO, J.R.F.; RIBEIRO, M.T. Padrão de infecção intramamária em rebanhos leiteiros: exame de todos os quartos mamários das vacas em lactação. Arquivo Brasileiro de Medicina Veterinária e Zootecnia, v.51, n.2, p.129-135, 1999.

COLDEBELLA, A. Contagem de células somáticas e produção de leite em vacas holandesas confinadas. 2003. $92 \mathrm{f}$. Tese (Doutorado em Agronomia - Área de Ciência Animal e Pastagens) - Escola Superior de Agricultura "Luiz de Queiróz", Universidade de São Paulo, Piracicaba, 2003.

COSTA, B. Homeopatia na cura e prevenção de doenças. Balde Branco, n.405, p.28-33, 1998.

COSTA, E. O. Importância da mastite na produção leiteira do país. Revista de Educação Continuada do CRMV-SP, v.1, p.3-9, 1998.

ERSKINE, R.J. Mastitis therapy: Problems and solutions. In: MEMORIAS DEL CONGRESO PANAMERICANO DE CONTROL DE MASTITIS Y
CALIDAD DE LA LECHE, 1., 1998, Mérida. Anais. Mérida, 1998. p.152-158.

FOX, L.K.; HANCOCK, D.D.; MICKELSON, A.; BRITTEN, A. Bulk tank milk analysis: Factors associated with appearance of Mycoplasma sp. in milk. Journal of Veterinary Medicine, v.50, p.235-240, 2003.

HILLERTON, J.E.; BERRY, E.A. Treating mastitis in the Cow - A tradition or an archaism. Journal of Applied Microbiology, v.98, n.2, p.1250-1255, 2005.

HOVI, M.; RODERICK, S. Mastits therapy in organic dairy herds. In: PROCEEDINGS OF THE BRITISH MASTITIS CONFERENCE, 1998, Stoneleigh, UK. Anais. Stoneleigh: Axient Institute for Animal Health, Milk Development Council/Novartis Animal Health, 1998. p.29-35.

HOLT, J.G. (Ed). Bergey's manual of determinative bacteriology. 9.ed. Baltimore: Willians; Wilkins, 1994. v.1. 816p.

LANGONI, H. Etiologia da mastite bovina subclinica e clínica: Perfil da sensibilidade microbiana, controle e repercussão na produção leiteira e na saúde pública. 1995. $200 f$. Tese (Livre docência em Zoonoses) - Faculdade de Medicina Veterinária e Zootecnia, Universidade Estadual Paulista, Botucatu, 1995.

LANGONI, H.; SILVA, A.V.; CABRAL, K.G.; DOMINGUES, P.F. Aspectos etiológicos na mastite bovina: flora bacteriana aeróbica. Revista Brasileira de Medicina Veterinária, v.20, n.5, p.204-209, 1998.

MANGIERI JUNIOR, R.; SOUTO, L.I.M.; MELVILLE, P.A.; BENITES, N.R. Avaliação de tratamento homeopático na mastite bovina subclínica. Revista Veterinária e Zootecnia, v.14, n.1, jun, p.91-99, 2007.

MEDRONHO, R.A. (Ed.) Epidemiologia. São Paulo: Editora Atheneu. 2004. 517p.

NADER-FILHO, A.; SCHOCKEN-ITURRINO, R.P.; ROSSI JUNIOR, O.D.; CEMBRANELLI, E.M. Prevalência e etiologia da mastite bovina na região de Ribeirão Preto, São Paulo. Pesquisa Veterinária Brasileira, Rio de Janeiro, v.5, n.2, p.53-56, 1985.

NATIONAL MASTITIS COUNCIL(US). Laboratory and field handbook on bovine Mastitis. Arlington: WD Hoard \& Sons, 1999. 222p.

OGOLA, H.; SHITANDI, A.; NANUA, J. Effect of mastitis on raw milk compositional quality. Journal of Veterinary Science, v.8, n.3, p.237-242, 2007.

OSTRENSKY, A. Efeitos de ambiente sobre a contagem de células somáticas no leite de vacas da raça Holandesa no Paraná. Curitiba, 1999. Dissertação (Mestrado em Ciências Veterinárias) - Setor de Ciências Agrárias, Universidade Federal do Paraná, Curitiba, 1999. 
PEREIRA, A.R.; MACHADO, P.F.; SARRIES, G.A. Contagem de células somáticas e características produtivas de vacas da raça holandesa em lactação. Scientia Agricola, v.58, n.4, p.649-654, 2001.

PHILPOT, W.N. Today's challenge to meet tomorrow's needs. In CONGRESO PANAMERICANO DE CONTROL DE MASTITIS Y CALIDAD DE LA LECHE, 1., 1998, Mérida. Memorias. Mérida, 1998. p.12-21.

PHILPOT, W.N.; NICKERSON, S.C. (Ed.) Mastitis counter attack, a strategy to combat mastitis. Naperville, Il: Babson Brothers, 1991. 150p.

PONTES NETTO, D.; LOPES, M.O.; OLIVEIRA, M.C.S.; NUNES, M.P.; MACHINSKI JUNIOR, M.; BOSQUIROLI, S.L.; BENATTO, A.; BENINI, A.; BOMBARDELLI, A.L.C.; VEDOVELLO FILHO, D.; MACHADO, E.; BELMONTE, I.L.; ALBERTON, M.; PEDROSO, P.P.; SCUCATO, E.S. Levantamento dos principais fármacos utilizados no rebanho leiteiro do estado do Paraná. Acta Scientiarium. Animal Sciences, v.96, n.1, p.145-151, 2005.

PYORALA, S. New strategies to prevent mastitis. Reproduction of Domestic Animals, v.37, p.211-216, 2002.

RIBEIRO, M.E.R.; PETRINI, L.A.; AITA, M.F.; BALBINOTTI, M.; STUMPF JUNIOR., W.; GOMES, J.F.; SCHRAMM, R.C.; MARTINS, P.R.; BARBOSA, R.S.

Relação entre mastite clínica, subclínica infecciosa e não infecciosa em unidades de produção leiteira na região sul do Rio Grande do Sul. Revista Brasileira de Agrociência, v.9, n.3, p.287-290, 2003.

ROMAIN, H.T.; ADESIYUN, A.A.; WEBB, L.A.; LAUCKNER, F.B. Study on risk factors and their association with subclinical mastitis in lactating dairy cows in Trinidad. Journal of Veterinary Medicine, v.47, p.257-271, 2000 .

RYSER, E.T. Microorganisms of importance in raw milk. In: CONGRESO PANAMERICANO DE CONTROL DE MASTITIS Y CALIDAD DE LA LECHE, 1., 1998, Mérida. Memorias. Mérida, 1998. p.236-239.

RUEGG, P.L. Mastitis Control. Milking and milk quality, v.405, p.1-10, 2001

SCHALM, O.W.; NOORLANDER, D.D. Experiments and observations leading to development of the California Mastitis Test. Journal of the American Veterinary Medical Association, v.130, p.199-204, 1957.
SEARCY, R.; REYES, O.; GUAJARDO, G. Control of subclinical bovine mastitis. British Homeopathic Journal, v.84, p.67-70, 1995.

SPRANGER, J. Test the effectiveness of antibiotic and homeopathic medication in the frame of herd reorganization of subclinical mastitis in milk cows. British Homeopathic Journal, v.89, n.1, p.62, 2000.

TIEFENTHALER, A. (Ed.) Homeopatia para animais domésticos e de produção. São Paulo: Andrei, 1996. 338p.

VARSHNEY, J.P.; NARESH, R. Evaluation of a homeopathic complex in the clinical management of udder diseases of riverine buffaloes. Homeopathy, v.93, p.17-20, 2004.

VIANA, L.C. Duração das infecções naturais por estafilococos coagulase negativos e contagem de células somáticas em vacas primíparas. 2000. 219f. Dissertação (Mestrado em Sanidade Animal) - Universidade Estadual de Londrina, Londrina, 2000.

VOLTOLINI, T.V.;SANTOS, G.T.;ZAMBOM, M.A.; RIBAS, N.P.; MÜLLER, E.E.; DAMASCENO, J.C.; ITAVO, L.C.V.; VEIGA, D.R. Influência dos estádios de lactação sobre a contagem de células somáticas do leite de vacas da raça holandesa e identificação de patógenos causadores de mastite no rebanho. Acta Scientiarum, v.23, n.4, p.961-699, 2001.

WICKS, H.C.F.; LEAVER, J.D. Influence of genetic merit and environment on somatic cell counts of Holstein-Friesian cows. The Veterinary Journal, v.172, p.52-57, 2006.

WINDIG, J.J.; CALUS, M.P.L.; DE JONG, G.; VEERKAMP, R.F. The association between somatic cell count patterns and milk production prior to mastitis. Livestock Production Science, v.96, p.291-299, 2005.

ZAFALON, L.F.; NADER-FILHO, A.; OLIVEIRA, J.V.; RESENDE, F.D. Comparação entre o California Mastitis Test e a contagem de células somáticas como métodos auxiliares para o diagnóstico da mastite subclínica bovina por Staphylococcus aureus e Corynebacterium spp. Boletim de Indústria Animal, v.62, n.1, p.63-69, 2005.

Recebido em 19/6/08

Aceito em 15/5/09 